\title{
Formation of $\mathrm{Rh}-\mathrm{Au}$ Core-Shell Nanoparticles on $\mathrm{TiO}_{2}(110)$ Surface Studied by STM and LEIS
}

\author{
L. Óvári, A. Berkó, ${ }^{*}$ N. Balázs, Z. Majzik, ${ }^{\dagger}$ and J. Kiss \\ Reaction Kinetics Research Laboratory, Institute of Nanochemistry and Catalysis, Chemical Research Center of \\ the Hungarian Academy of Sciences and Department of Physical Chemistry and Material Science, University of \\ Szeged, H-6720 Szeged, Dóm tér 7, Hungary. ${ }^{\dagger}$ Also a member of the staff of the Department of Thin Films, \\ Institute of Physics of the Academy of Sciences of Czech Republic, Cukrovarnicka 10, Prague 6,
} 16253 Czech Republic.

Received July 21, 2009. Revised Manuscript Received October 19, 2009

\begin{abstract}
$\mathrm{Rh}-\mathrm{Au}$ core-shell nanoparticles were fabricated on $\mathrm{TiO}_{2}(110)$ surface by physical vapor deposition (PVD) of $\mathrm{Rh}$ followed by exposure of Au at elevated sample temperature $(500 \mathrm{~K})$. The morphology of the bimetallic particles was checked by scanning tunneling microscopy (STM). The chemical composition of the particles was characterized by low energy ion scattering (LEIS) method. It was shown that the "seeding + growing" method described previously for growth of monometallic particles in narrow size distribution (Berkó, A. et al. J. Catal. 1999, 182, 511) can also be applied for fabrication of bimetallic nanoparticles. The large mean free path of surface diffusion of gold on the oxide support makes the accumulation of Au possible exclusively on the Rh seeds formed in the first step of the procedure. By performing careful STM and LEIS experiments, it was proven that, for appropriate Au and Rh coverages, the postdeposited $\mathrm{Au}$ completely and uniformly covers the $\mathrm{Rh}$ nanoparticles.
\end{abstract}

\section{Introduction}

The mechanism of the formation of metal nanoparticles on oxide surfaces not only is an important theoretical issue, but also represents a key process in the fabrication of nanostructured ultrathin films. ${ }^{1-3}$ The study of $2 \mathrm{D}$ (planar) model catalysts prepared by "bottom-up" techniques provided an excellent example of how the complexity of the material systems can be increased step-by-step in order to investigate crucial issues related to the chemical reactivity of nanoparticles. ${ }^{4-9}$ One of these important questions is understanding the origin of the efficiency of so-called bimetallic catalysts. ${ }^{10-14}$ In spite of the widespread investigations of metal-on-metal systems, the atomic-scale study

*Corresponding author. Prof. András Berkó, H-6701 Szeged, P.O. Box 168, Hungary. Phone: +36 62544 646. Fax: +36 62420 678. E-mail: aberko@ chem.u-szeged.hu.

(1) Bäumer, M.; Freund, H.-J. Prog. Surf. Sci. 1999, 61, 127

(2) Campbell, C. T. Surf. Sci. Rep. 1997, 27(1-3), 1.

(3) Fu, Q.; Wagner, T. Surf. Sci. Rep. 2007, 62, 431.

(4) Eppler, A. S.; Rupprechter, G.; Guczi, L.; Somorjai, G. A. J. Phvs. Chem. B

1997, 101(48), 9973.

(5) Berkó, A.; Solymosi, F. J. Catal. 1999, 183, 91.

(6) Berkó, A.; Klivényi, G.; Solymosi, F. J. Catal. 1999, 182, 511

(7) Frank, M.; Andersson, S.; Libuda, J.; Stempel, S.; Sandell, A.; Brena, B.; Giertz, A.; Brühwiler, P. A.; Bäumer, M.; Martensson, N.; Freund, H.-J. Chem. Phvs. Lett. 1997, 279, 92.

(8) Besenbacher, F.; Lauritsen, J. V.; Wendt, S. Nanotoday 2007, 2(4), 30

(9) Meier, D. C.; Goodman, D. W. J. Am. Chem. Soc. 2004, 126, 1892.

(10) Brune, H. Surf. Sci. Rep. 1998, 31, 121.

(11) Ruban, A. V.; Skriver, H. L.; Norskov, J. K. In Surface allovs and allov surfaces. Woodruff, D. P., Ed.; Amsterdam, 2002; Vol 10, p 1.

(12) Chen, J. G.; Menning, C. A.; Zellner, M. B. Surf. Sci. Rep. 2008, 63, 201.

(13) Greeley, J.; Jens, K.; Nørskov, J. K. Surf. Sci. 2007, 601, 1590.

(14) Hoster, H. E.; Bergbriter, A.; Erne, P. M.; Hager, T.; Rauscher, H.; Behm,

R. J. Phvs. Chem. Chem. Phvs. 2008, 10, 3812

(15) Carlsson, A. F.; Naschitzki, M.; Bäumer, M.; Freund, H.-J. J.Phvs. Chem. $\underline{B}$ 2003, 107, 778 .

(16) Napetsching, E.; Schmid, M.; Varga, P. Surf. Sci. 2007, 601, 3233

(17) Felicissimo, M. P.; Martyanov, O. N.; Risse, T.; Freund, H.-J. Surf. Sci. 2007, 601, 2105.

(18) Ozturk, O.; Park, J. B.; Ma, S.; Ratliff, J. S.; Zhou, J.; Mullins, D. R.; Chen, D. A. Surf. Sci. 2007, 601, 3099.

(19) Park, J. B.; Ratliff, J. S.; Ma, S.; Chen, D. A. Surf. Sci. 2006, 600, 2913. of the bimetallic nanoparticles is rather incomplete. ${ }^{15-20}$ Nevertheless, the studies on monolayer bimetallic surfaces led to very detailed knowledge- even at the atomic scale- of the interaction between the components. ${ }^{10,12,21}$ The bulk-phase alloying, dissolution, and segregation processes are theoretically well described, and they are experimentally characterized in detail as well. ${ }^{22,23}$ After comparison of these data to the results on metal-on-metal systems, it was concluded that the properties of the atomically thin layers of the same components can exhibit substantial deviation from the behavior in the bulk. ${ }^{12}$ It is known, for example, that nonmiscible materials can form a surface alloy or a dissolved layer in the subsurface region. In the case of miscible metals, the activation energy for the near-surface processes (immersion in sublayer, site exchange) is usually much lower than that for bulk diffusion, segregation, or dissolution. ${ }^{14}$ Consequently, the mixing or separation of the constitutent atoms in a nanoparticle is a rather common phenomenon at room temperature, in which the positions of the component atoms are largely determined by their (bulk and surface) thermodynamic properties. It is also known that electronic properties of (bi)metallic nanoparticles can be different from their bulk characteristics, which can also lead to different alloying capabilities. For example, although the platinum-gold phase diagram refers to a wide miscibility gap due to limited mutual solubility of the components, the smaller nanoparticles $(d<3 \mathrm{~nm})$ form homogeneous alloys, because rehybridization due to band formation does not take place and all atoms retain their atomic electronic configuration. $^{24}$

Regarding the in situ formation of bimetallic nanoparticles on solid-state surfaces (supports), an important issue is how the

(20) Park, J. B.; Conner, S. F.; Chen, D. A. J. Phys. Chem. C 2008, 112, 5490.

(21) Rodriguez, J. A. Surf. Sci. Rep. 1996, 24, 223.

(22) Massalski, T., Okamato, H., Subramanian, P. R., and Kacprzak, L., Eds.; Binary Alloy Phase Diagrams, Vol. 1 and 2; ASMI: Materials Park, OH, 1990.

(23) Mezey, L. Z.; Giber, J. Jpn. J. Appl. Phvs. 1982, 21, 1569.

(24) Bond, G. C. Platinum Metals Rev. 2007, $51(2), 63$. 
constituent atoms can be brought together. This question points to the need for knowledge of surface diffusion properties of the components and the kinetic parameters of this process. The surface mobility of different metals on different oxide surfaces has been expansively studied throughout the past decade; ${ }^{1,2,25}$ accordingly, all the most important considerations and devices are well-established both theoretically and experimentally for tailored formation and surface science level study of the supported bimetallic nanoparticles. In several recent works, we investigated the codeposition of $\mathrm{Au}$ with some other metals: $\mathrm{Mo},{ }^{26,27} \mathrm{Rh},{ }^{27,28}$ $\mathrm{K}^{29}$ These studies connect to the recent hot topic on development of efficient Au catalysts for low-temperature preferential CO oxidation (PROX-catalyst). It turned out that both the deposition sequence and the chemical nature of the codeposited metals dramatically influence the size distribution of Au nanoparticles; moreover, the oxidation state of the support plays also a crucial role in the particle formation. When $\mathrm{Rh}$ was deposited on a $\mathrm{TiO}_{2}(110)$ surface previously covered by gold, $\mathrm{Rh}$ atoms impinged to Au clusters moved to subsurface sites; consequently, the outermost atomic layer of these clusters remained almost pure gold. ${ }^{28}$ This process is driven by the large difference in surface free energies of $\mathrm{Rh}$ and $\mathrm{Au}$. In accordance with other investigations, the observed effect showed that, though $\mathrm{Rh}$ and Au are practically immiscible in bulk, ${ }^{30}$ they can form surface alloy by thermal ${ }^{31}$ and nonthermal place exchange, ${ }^{32}$ or by thermal diffusion of Au atoms on the cluster surface leading to the stabilization of Rh atoms at subsurface sites. ${ }^{31}$ It was also shown that a relatively high temperature of $\sim 1325 \mathrm{~K}$ is necessary to break $\mathrm{Au}-\mathrm{Rh}$ bonds in the case of $\mathrm{Au} / \mathrm{Rh}(111)$ system. ${ }^{33}$

The experimental and theoretical results mentioned above alerted us to a possible procedure for templated formation of bimetallic nanoclusters in predetermined mean size and surface distribution. The idea was already exploited in our earlier studies in which monometallic $\mathrm{Rh}, \mathrm{Pt}$, and Ir nanoparticles were fabricated in narrow size distribution by the so-called "seeding + growing" method. ${ }^{6,34,35}$ Recently, a similar concept was also described for producing bimetallic particles on different oxide supports. ${ }^{16-19}$ In the present work, the formation of $\mathrm{Rh}-\mathrm{Au}$ core-shell nanoparticles on $\mathrm{TiO}_{2}(110)$ surfaces is studied by means of scanning tunneling microscopy (STM) and low-energy ion scattering (LEIS) methods.

\section{Experimental Section}

The experiments were executed in two different ultra-highvacuum (UHV) systems evacuated down to $5 \times 10^{-8} \mathrm{~Pa}$. The first one was equipped by a hemispherical analyzer (Leybold) for performing low-energy scattering (LEIS) and Auger-electron (AES) spectroscopy measurements. In the second UHV chamber, a commercial scanning tunneling microscope (WA-Technology), a cylindrical mirror analyzer with a concentric electron gun (Staib-DESA-100), and a quadrupole mass spectrometer (Balzers-PRISMA) was built in where the STM and AES mea-

(25) Diebold, U. Surf. Sci. Rep. 2003, 48, 53.

(26) Bugyi, L.; Berkó, A.; Ovári, L.; Kiss, A. M.; Kiss, J. Surf. Sci. 2008, 602, 1650.

(27) Kiss, J.; Óvári, L.; Deák, L.; Berkó, A. React. Kinet. Catal. Lett. 2009, 96, 391.

(28) Óvári, L.; Bugyi, L.; Majzik, Z.; Berkó, A.; Kiss, J. J. Phvs. Chem. C 2008, 112(46), 18011

(29) Kiss, A. M.; Svec, M.; Berkó, A. Surf. Sci. 2006, 600, 3352.

(30) Curtarolo, S.; Morgan, D.; Ceder, G. Computer Coupling of Phase

Diagrams and Thermochemistry 2005, 29, 163.

(31) Altman, E. I.; Colton, R. J. Surf. Sci. 1994, 304, L400.

(32) Chado, I.; Scheurer, F.; Bucher, J. P. Phvs. Rev. B 2001, 64, 094410.

(33) Rodriguez, J. A.; Kuhn, M.; Hrbek, J. J. Phvs. Chem. 1996, 100, 3799

(34) Berkó, A.; Solymosi, F. Surf. Sci. 1998, 400, 281.

(35) Berkó, A.; Szöko, J.; Solymosi, F. Surf. Sci. 2003, 532-535, 390. surements were carried out. Note that, in the present work, the AES and MS techniques were mainly applied for checking the surface/ad-metal cleanliness and the gas-phase composition. In order to avoid the need of transfer and air-exposure of the probes, two similar rutile $\mathrm{TiO}_{2}(110)$ samples (Pi-Kem) were studied in parallel in the two UHV sytems.

A Specs IQE 12/38 ion source was used for generation of LEIS spectra. $\mathrm{He}^{+}$ions of $800 \mathrm{eV}$ kinetic energy were applied at a low ion flux equal to $0.03 \mu \mathrm{A} / \mathrm{cm}^{2}$, which was necessary to avoid the sputtering of surfaces. Note that LEIS supplies information only on the outermost atomic layer, when performed with noble gas ions. The incident and detection angles were $50^{\circ}$ (with respect to surface normal), while the scattering angle was $95^{\circ}$. The ions (LEIS) were analyzed by a Leybold HA as mentioned above.

The STM images of $256 \times 256$ pixels were generally recorded in constant-current mode at a bias of $+1.5 \mathrm{~V}$ (on the sample) and tunneling current of $0.05 \mathrm{nA}$ with an electrochemically etched $\mathrm{W}$ tip. An image was recorded within 3 min on average. Because of the importance of the particle statistics in this work, special attention was paid to choosing appropriate surface regions to record. First, large-scale images of $200 \times 200 \mathrm{~nm}^{2}$ were detected on macroscopically different areas of the sample (within 1-2 $\mathrm{mm}$ ); after comparison of the images obtained in this way, we selected characteristic regions and recorded at least 20-30 highresolution images $\left(20 \times 20 \mathrm{~nm}^{2}\right)$; after imaging, we chose the best $3-5$ records (each containing more than $40-50$ particles) for the statistical evaluation of the particle morphology. It is important to remark that image processing software (SPIP) developed by Image Metrology was applied for automatic particle identification and determination of their parameters. In cases where this method was not applicable (agglomerized particles), the particle morphology was separatively determined for each particle. The $X-Y-Z$ calibration of the STM images was performed by measuring the characteristic morphological parameters of the $\mathrm{TiO}_{2}(110)-(1 \times 1)$ support (lateral unit cell, $0.296 \times 0.650 \mathrm{~nm}^{2}$; height of [001] oriented step, $0.297 \mathrm{~nm}$ ). Special and careful tip conditioning was applied in order to obtain reliable particle sizes. This contained not only coarse and fine bias-pulse treatments, but also an extended in situ "annealing" of the tip-end at $180 \mathrm{~V}$ and $100 \mathrm{nA}$ in feedback mode for $10-20 \mathrm{~min}$.

The $\mathrm{TiO}_{2}(110)$ single crystal of $10 \times 10 \times 1 \mathrm{~mm}^{3}$ in the LEIS chamber was fixed to a Ta foil by a UHV compatible oxide adhesive (Ceramobond 571, Aremco) and was heated by a W filament placed behind the Ta foil. In the STM chamber, the $5 \times$ $5 \times 1 \mathrm{~mm}^{3}$ crystal was directly fixed to a Ta filament by the same oxide adhesive, and it was mounted on a transferable sample holder. The probe was annealed by current flowing through the Ta filament. In both chambers, the probe temperature was measured by a chromel-alumel (K-type) thermocouple stuck to the side of the samples by the same oxide adhesive. The initial cleaning was started by a gradual increase of the temperature up to $1050 \mathrm{~K}$, and it was continued by $\mathrm{Ar}^{+}$bombardment at $1000 \mathrm{~K}$ with stepwise decreased ion energies of $2,1.5$, and $1 \mathrm{keV}$ (an average current density of $4-6 \mu \mathrm{A} / \mathrm{cm}^{2}$ ) for several hours. This procedure resulted not only in the purification of the samples (mainly getting rid of $\mathrm{Ca}$ and $\mathrm{K}$ contamination), but also some reduction in the subsurface layer (making the samples conductive), and made it possible to avoid charging through the spectroscopy and microscopy measurements. In order to reset the $\mathrm{TiO}_{2}$ stoichiometry, from time to time, the samples were reoxidized in $5 \times 10^{-2} \mathrm{~Pa}$ oxygen for $10-20 \mathrm{~min}$ at $900 \mathrm{~K}$. The final treatment was usually a short annealing at $1050 \mathrm{~K}$ in UHV. For the measurements presented in this work, both $(1 \times 1)$ and $(1 \times 2)$ ordered surfaces were applied.

$\mathrm{Au}$ and $\mathrm{Rh}$ were deposited by a commercial 4-pocket PVDsource (Oxford Applied Research). In the case of Au, a carbon crucible was filled by pieces of high-purity $(99.95 \%)$ gold, while in the case of Rh, a high-purity (99.95\%) Rh rod was applied. In the STM chamber, the surface concentrations of the deposited metals 
were estimated from the volume of the nanoparticles separated clearly from each other. In the other chamber, LEIS and XPS methods were used for the same purpose..$^{26,28}$ The cross-calibration of the metal coverages in the two UHV systems was performed by AES measurements. In general, the accuracy for the metal coverages presented in this work is not worse than $\pm 15 \%$. The coverage of the deposited metals is expressed in equivalent monolayers defined as the amount of metal related to a layer arranged in a close-packed (111) structure and covering the substrate with a single atomic layer. For $\mathrm{Au}$ and $\mathrm{Rh}$, the monolayer equivalent (ML) corresponds to $1.39 \times 10^{15} \mathrm{Au}$-atom/ $\mathrm{cm}^{2}$ (the atom density of $\mathrm{Au}(111)$ surface) and $1.60 \times 10^{15} \mathrm{Rh}-$ atom $/ \mathrm{cm}^{2}$ (the atom density of $\mathrm{Rh}(111)$ surface), respectively. In this study, the deposition rates of approximately $0.5 \mathrm{ML} / \mathrm{min}$ and 2.0 $\mathrm{ML} / \mathrm{min}$ were applied for $\mathrm{Au}$ and $\mathrm{Rh}$, respectively.

\section{Results}

3.1. Scanning Tunneling Microscopy Measurements. It was shown in our earlier investigations that the composition and morphology of the bimetallic nanoparticles produced by PVD of two metals depend sensitively on the sequence of the deposition. ${ }^{26-28}$ In the present work, Rh was deposited first. This metal bonds more strongly to the $\mathrm{TiO}_{2}(110)$ substrate than gold, and in this way, it forms nanoclusters in a higher dispersion. This behavior is also a consequence of the higher activation energy of diffusion of $\mathrm{Rh}$ than that of Au. Moreover, since the surface free energy of Au is lower than that of Rh, the former metal tends to cover $\mathrm{Rh}^{31,32}$ These properties give us a chance to seed the surface by Rh and to grow a gold capping layer on top of these $\mathrm{Rh}$-seeds without the formation of any separate pure Au nanoparticles.

Regarding the support, it is well-known that the actual morphology of $\mathrm{TiO}_{2}$ single crystal surfaces depends not only on the last treatment, but also on the former treatments of the samples. ${ }^{25}$ As a function of the surface oxidation state, the following series of the (quasi-)ordered arrangements were detected: (1) stoichiometric (bulk terminated) $1 \times 1$; $(2)(1 \times 1)$ surface decorated with oxygen defects of reduced $0 \mathrm{D}$ dots and $1 \mathrm{D}$ strings (stripes) of $\mathrm{Ti}_{2} \mathrm{O}_{3}$ phase; (3) strongly covered surface by $\mathrm{Ti}_{2} \mathrm{O}_{3}$ strings in different $(1 \times n)$ structures; $(4)(1 \times 2)$ reconstructed surface in highly ordered arrangement; $(5)$ cross-linked $(1 \times 2)$ reconstructed surface; (6) unordered polycrystalline surface. In the present work, the samples exhibiting the states of (2) or (4) were used where the former one was called $(1 \times 1)$ and the latter one $(1 \times 2)$ surface. Figure 1A,B shows the $(1 \times 1)$ surface on larger and atomic scale. On the former image of $50 \times 50 \mathrm{~nm}^{2}$, extended terraces decorated by some $0 \mathrm{D}$ dots and $1 \mathrm{D}$ strands of length $5-15 \mathrm{~nm}$ with an approximate concentration of $1 \times 10^{12} \mathrm{~cm}^{-2}$. These features can be identified with the reduced phase of $\mathrm{Ti}_{2} \mathrm{O}_{3}$ (see below the description of the $(1 \times 2)$ reconstructed surface). The image of $5 \times 5 \mathrm{~nm}^{2}$ in Figure 1B exhibits bright rows separated by $0.65 \mathrm{~nm}$. According to the comparative evaluation given by Diebold for various images obtained in different contrasts, the bright strands here can be indentified with the position of bridging oxygen atoms ("unconventional contrast") and the darker sites along the bright rows can be assigned to oxygen defects. ${ }^{25}$ More details about the bulk terminated $(1 \times 1)$ surface containing different defect sites can be found in several recent papers. ${ }^{36,37}$ Several studies on the long-range ordered

(36) Wendt, S.; Schaub, R.; Matthiesen, J.; Vestergaard, E. K.; Wahlström, E.; Rasmussen, M. D.; Thostrup, P.; Molina, L. M.; Lægsgaard, E.; Stensgaard, I.; Hammer, B.; Besenbacher, F. Surf. Sci. 2005, 598, 226.

(37) Wendt, S.; Sprunger, P. P.; Lira, S.; Madsen, G. K. H.; Li, Z.; Hansen, J.Ø.; Matthiesen, J.; Blekinge-Rasmussen, A.; Lægsgaard, E.; Hammer, B.; Besenbacher, F. Sience 2008, 320, 1755.

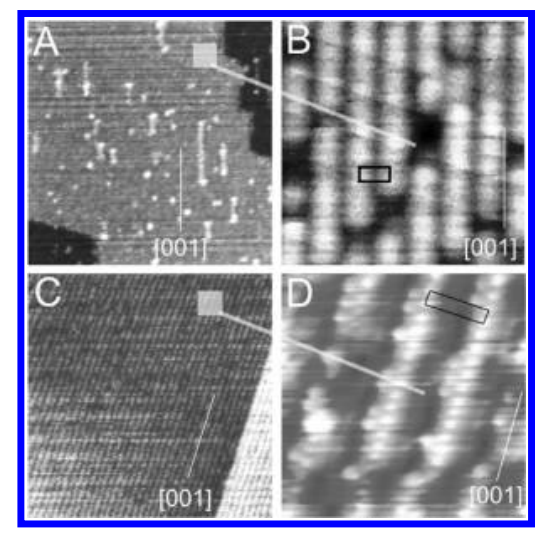

Figure 1. Characteristic STM images recorded on the supports $(\mathrm{A}, \mathrm{B}) \mathrm{TiO}_{2}(110)-(1 \times 1)$ and $(\mathrm{C}, \mathrm{D}) \mathrm{TiO}_{2}(110)-(1 \times 2)$ applied in this work. Image size: $(A, C) 50 \times 50 \mathrm{~nm}^{2} ;(B, D) 5 \times 5 \mathrm{~nm}^{2}$.

$\mathrm{TiO}_{2}(110)-(1 \times 2)$ surface were also reported last year; ${ }^{25,38,39}$ however, this structure received much less attention than the stoichiometric $(1 \times 1)$ surface. Figure $1 \mathrm{C}$ shows the typical STM image $\left(50 \times 50 \mathrm{~nm}^{2}\right)$ for our samples exhibiting the $(1 \times 2)$ reconstructed arrangement. As can be seen, large terraces with [001] oriented stripes running a distance of $1.30 \mathrm{~nm}$ from each other dominate this surface pattern. The strings seem to be disturbed, although their shape is rather uniform everywhere on the surface (Figure 1 C,D). They can be assigned to an 1D reduced phase $\left(\mathrm{Ti}_{2} \mathrm{O}_{3}\right)$ described previously. ${ }^{38,39}$ In our case, the atomiclevel image $\left(5 \times 5 \mathrm{~nm}^{2}\right)$ of the strands (strings) shows that they consist of two subrows containing a lot of defects in an asymmetric way: one of the row pairs exhibits more defects than the neighboring row (Figure 1D). Nevertheless, the bright spots along the [001] direction are separated by $0.29 \mathrm{~nm}$, which corresponds to the shorter vector of the $(1 \times 1)$ unit cell; accordingly, they can be identified to $\mathrm{Ti}^{4+}$ sites. The $(1 \times 2)$ unit cell is also indicated in this figure.

In the following part, the formation of $\mathrm{Au}-\mathrm{Rh}$ bimetallic nanoparticles will be presented on a $\mathrm{TiO}_{2}(110)-(1 \times 1)$ surface (Figure 2). The fabrication procedure starts with deposition of $\mathrm{Rh}$. The STM images of $20 \times 20 \mathrm{~nm}^{2}$ and $50 \times 50 \mathrm{~nm}^{2}$ shown in Figure 2A,B were recorded after the deposition of $0.34( \pm 0.03)$ ML of Rh onto the clean $\mathrm{TiO}_{2}(110)-(1 \times 1)$ surface at $500 \mathrm{~K}$. The coverage was obtained from the summarized volume of the particles. The diameter of the particles changes in the range 1.5-3.0 $\mathrm{nm}$ and the larger ones are 2 layers high, assuming an average layer thickness of $0.225 \mathrm{~nm}$ (the layer-to-layer distances for $\mathrm{Au}(111)$ and $\mathrm{Rh}(111)$ are 0.235 and $0.218 \mathrm{~nm}$, respectively). Regarding the size of these particles, they consist of approximately 100-300 Rh atoms (see also Figure 3). On the basis of at least five images of good quality recorded on different surface regions, a particle concentration of $4.0( \pm 0.3) \times 10^{12} \mathrm{~cm}^{-2}$ was obtained. The analysis of the images has shown that there is no clear preference for occupation of the dark or bright rows (or even of terrace edges). This $\mathrm{Rh} / \mathrm{TiO}_{2}(110)-(1 \times 1)$ sample was sequentially exposed to gold (Figure $2 \mathrm{C}-\mathrm{F}$ and Figure 3 ). The following coverage values were calculated for the different cases presented in Figure 2: (C and D) addition of 0.38 ML of Au to the predeposited Rh (0.34 ML) mentioned above; (E and F) further deposition of 1.30 ML of Au (total $\mathrm{Rh}+\mathrm{Au}$ coverage of 2.02 ML). Regarding the surface concentration of the particles, the most

(38) Fischer, S.; Munz, A. W.; Schierbaum, K.-D.; Göpel, W. Surf. Sci. 1995, 337,17 . L41.

(39) Takakusagi, S.; Fukui, K.; Nariyuki, F.; Iwasawa, Y. Surf. Sci. 2003, 523, 


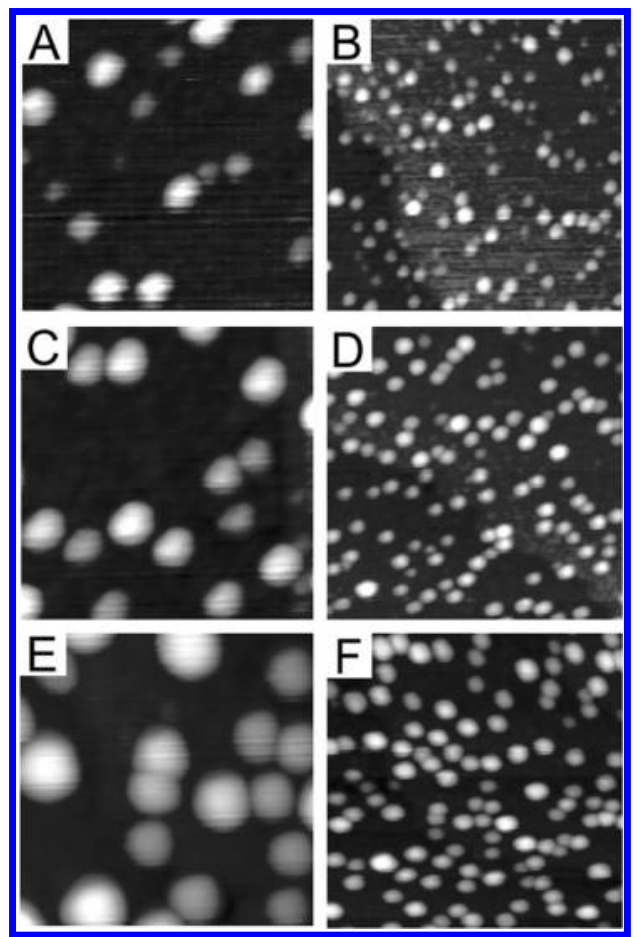

Figure 2. STM images recorded on (A,B) 0.34 ML Rh deposited $\mathrm{TiO}_{2}(110)-(1 \times 1)$ surface followed by exposure of Au at $500 \mathrm{~K}$ in two subsequent steps: (C,D) $0.38 \mathrm{ML} ;(\mathrm{E}, \mathrm{F})+1.30 \mathrm{ML}$. The size of the images: $(A, C, E) 20 \times 20 \mathrm{~nm}^{2} ;(B, D, F) 50 \times 50 \mathrm{~nm}^{2}$.

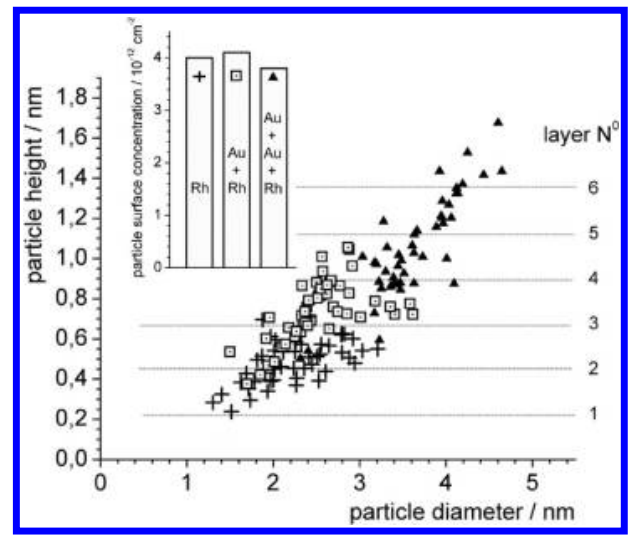

Figure 3. Map of the diameter and height of the particles detected by STM for the three stages exhibited in Figure 2. Inset: change of the particle surface concentration for the three different stages.

important feature is that the deposition of $\mathrm{Au}$ does not cause any systematic change in the number of the particles, as is shown in the insert graph in Figure 3. From this fact, it can be concluded that the growth of existing metal particles is highly preferred at the deposition temperature of $500 \mathrm{~K}$ and for the average seed-to-seed distance (appr. $5 \mathrm{~nm}$ ) applied here. For the detailed analysis of the change of the particle morphology, a height-diameter map of the nanoparticles is plotted in Figure 3. The data points were taken from similar images presented in Figure $2 \mathrm{~A}-\mathrm{F}$. It can be seen that most of the initial Rh seeds are 2 layers thick and the diameter of these particles varies in the range 1.5-3.0 $\mathrm{nm}$. The postdeposition of Au results in an increase in both the diameter and the height of the particles. On the effect of the first $\mathrm{Au}$ exposure $(+0.38 \mathrm{ML})$, the particles become 3-4 layers thick with a characteristic diameter of $2-3.5 \mathrm{~nm}$. These data indicate that $\mathrm{Au}$ covers the rhodium particles in approxi-

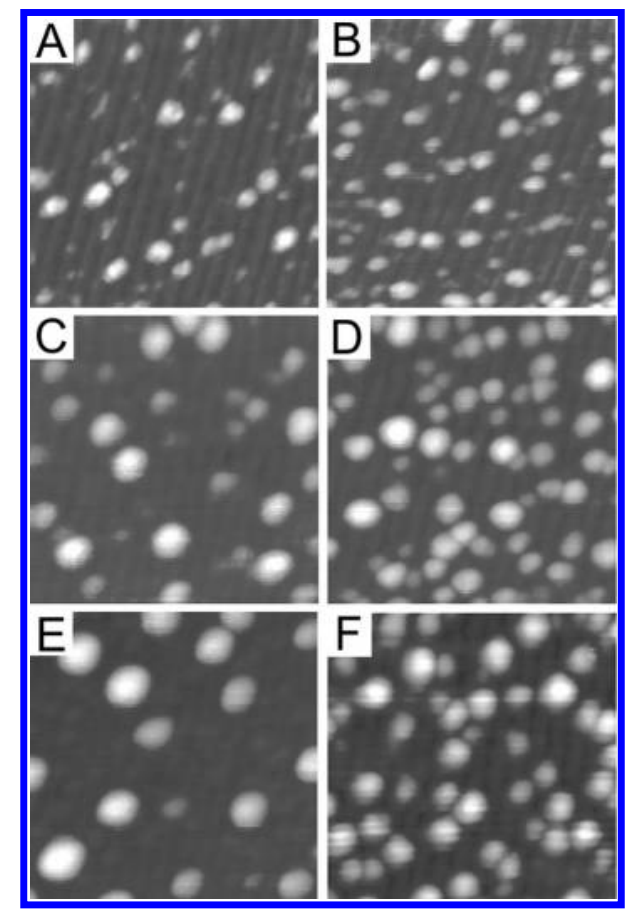

Figure 4. STM images $\left(20 \times 20 \mathrm{~nm}^{2}\right)$ recorded on (A) $0.27 \mathrm{ML}$ and (B) $0.42 \mathrm{ML}$ Rh deposited $\mathrm{TiO}_{2}(110)-(1 \times 2)$ surface followed by exposure of $\mathrm{Au}$ at $500 \mathrm{~K}$ in two subsequent steps: (C) $0.35 \mathrm{ML}$ and (E) +0.26 ML onto (A); (D) 0.42 ML and (F) +0.30 ML onto (B).

mately 1-2 ML thickness both on the top and on the side (perimeter). The subsequent deposition of $\mathrm{Au}(+1.30 \mathrm{ML})$ results in an expressed further enhancement of the average particle height (4-6 atomic layers) and diameter $(3.2-4.6 \mathrm{~nm})$ by formation of 2-3 additional $\mathrm{Au}$ layers on both the top and the perimeter (Figure 3).

The formation of $\mathrm{Au}-\mathrm{Rh}$ bimetallic particles was followed also on a $\mathrm{TiO}_{2}(110)-(1 \times 2)$ reconstructed surface for two different initial Rh coverages: $0.27( \pm 0.03) \mathrm{ML}$ and $0.42( \pm 0.04)$ $\mathrm{ML}$ in Figure $4 \mathrm{~A}$ and $\mathrm{B}$, respectively. The size of all images in this figure is $20 \times 20 \mathrm{~nm}^{2}$. Rh was deposited onto a clean $\mathrm{TiO}_{2}$ $(110)-(1 \times 2)$ surface at $500 \mathrm{~K}$. It is important to remark that a partial encapsulation of supported $\mathrm{Rh}$ particles by titania phase cannot be excluded on reconstructed $\mathrm{TiO}_{2}(110)$ surfaces at this temperature. ${ }^{18,40,41}$ The diameter of the nanoparticles formed in this way varies in the range of $0.8-2.0 \mathrm{~nm}$, and they are $1-2$ layers thick assuming an average interlayer distance of $0.225 \mathrm{~nm}$ (see above). The main difference between the two coverages is the surface concentration of the $\mathrm{Rh}$ particles, while their mean size is quite similar. On the basis of images recorded on different surface regions, the following particle concentrations were obtained: $7.0( \pm 1.5) \times 10^{12} \mathrm{~cm}^{-2}$ and $15( \pm 2.0) \times 10^{12} \mathrm{~cm}^{-2}$. According to the size of the particles, they consist of 50-200 Rh atoms. The parallel rows running in the direction of [001] are characteristic morphological features of the $\mathrm{TiO}_{2}(110)-(1 \times 2)$ surface. The analysis of the images has shown that the Rh seeds appear on the bright strings with a slightly higher probability. These $\mathrm{Rh} / \mathrm{TiO}_{2}$ $(110)-(1 \times 2)$ templates were sequentially exposed to gold two times (Figure $4 \mathrm{C}-\mathrm{F}$ ). As mentioned above, the total metal $(\mathrm{Rh}+\mathrm{Au})$ coverage was determined from the summarized particle volume. In this way, the following coverage values were calculated for the different cases presented in Figure 4: (C) addition of $0.35 \mathrm{ML}$ of $\mathrm{Au}$ to the predeposited 0.27 ML of Rh; (E) further

(40) Berkó, A.; Ménesi, G.; Solymosi, F. Surf. Sci. 1997, 372, 202.

(41) Berkó, A; Ulrych, I; Prince, K. C. J. Chem. Phvs. 1998, 102, 3379. 


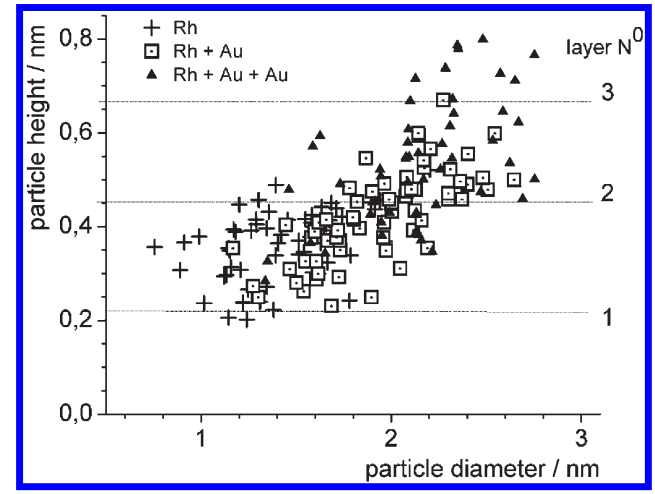

Figure 5. Map of the diameter and height of the particles detected by STM for the three stages exhibited in Figure 4.

deposition of $\mathrm{Au} 0.26 \mathrm{ML}$; (D) addition of $\mathrm{Au} 0.42 \mathrm{ML}$ to the predeposited Rh of $0.42 \mathrm{ML}$; (F) further exposure of Au 0.30 ML. Regarding the surface density of the particles, the most important feature is that the deposition of $\mathrm{Au}$ does not cause any increase in the lateral concentration of the particles (on the contrary, a slight decrease of $25-30 \%$ can be observed), similar to the case of the $(1 \times 1)$ bulk terminated oxide surface presented above. From this fact, it can be concluded that an additional nucleation of pure $\mathrm{Au}$ clusters is strongly suppressed for all $\mathrm{Rh} / \mathrm{TiO} \mathrm{O}_{2}$ templates and conditions (temperature, deposition rate, average distance of $\mathrm{Rh}$ seeds) applied in this work. For detailed analysis of the change of the particle morphology, a map of height and diameter of the individual nanoparticles is plotted in Figure 5. The data points belong to the surfaces shown in Figure 4B,D,F. For each stage of the series, three images (altogether of 150-200 nanoparticles) were analyzed; however, for a better visibility, only a third of them were selected for the plots in Figure 5. As can be seen, the initial $\mathrm{Rh}$ seeds are 1-2 layers thick and their average diameter is $1.3( \pm 0.6) \mathrm{nm}$ (Figure 5). On the effect of the first Au exposure $(+0.42 \mathrm{ML})$, the larger particles become 2-3 layers in height with a characteristic diameter of $2.0( \pm 0.8) \mathrm{nm}$. These data indicate that approximately 1-ML-thick Au covers the Rh particles both on the top and on the side (perimeter). The further deposition of $\mathrm{Au}$ $(+0.29 \mathrm{ML})$ results in an enhancement of the average particle height (formation of an additional Au layer), although the average diameter of the particles increases only slightly (Figure 5).

In the following section, we present comparative experiments on the thermal stability of $\mathrm{Rh}, \mathrm{Au}$, and $\mathrm{Au} / \mathrm{Rh}$ particles supported on $\mathrm{TiO}_{2}(110)-(1 \times 2)$ surfaces. Three different initial states were produced: (i) $0.49 \mathrm{ML}$ Au deposited at $500 \mathrm{~K}$; (ii) predeposition of $0.28 \mathrm{ML}$ of $\mathrm{Rh}$ followed by exposure of $0.67 \mathrm{ML}$ of $\mathrm{Au}$ at $500 \mathrm{~K}$; (iii) $0.46 \mathrm{ML}$ Rh deposited at $500 \mathrm{~K}$ (Figure 6A). Morphological changes on annealing at elevated temperatures for $5 \mathrm{~min}$ were followed by recording STM images. The size of the images shown in this figure is $50 \times 50 \mathrm{~nm}^{2}$. The left column in Figure 6 exhibits the thermal stability of the pure Au particles. It can be seen that $\mathrm{Au}$ forms relatively large nanoparticles (diameter of 4-5 nm, height of 3-4 atomic layers) in an average separation of 10-15 $\mathrm{nm}$ at $500 \mathrm{~K}$, and this particle distribution does not change substantially up to $700 \mathrm{~K}$. Above this temperature, the number of surface Au nanoparticles gradually decreases without a pronounced increase of their mean size, and above $1000 \mathrm{~K}$, they disappear from the substrate. This behavior is in full harmony with our previous results suggesting that, in the range 700-900 K, the thermally induced Ostwald ripening process may be accompanied by desorption of single $\mathrm{Au}$ atoms dispatched from more stable crystallites. ${ }^{29}$ Both the total surface coverage and the concentration of the $\mathrm{Au}$ nanoparticles decreases gradually to

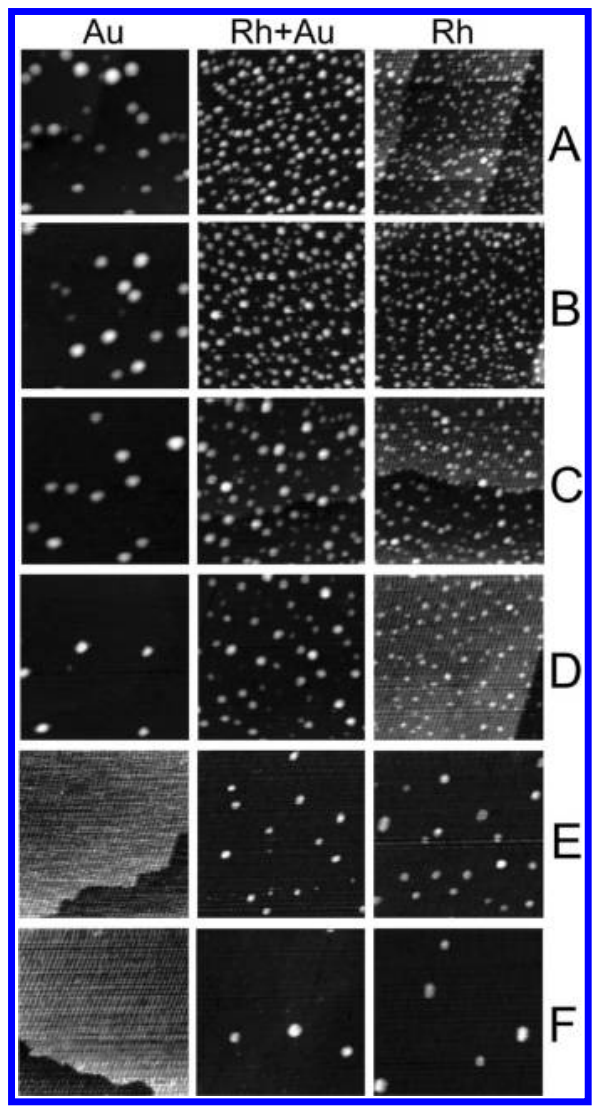

Figure 6. Effects of thermal treatments on the morphology of the $0.50 \mathrm{ML} \mathrm{Au}$ (left column), 0.28 ML Rh +0.67 ML Au (middle column), and $0.46 \mathrm{ML} \mathrm{Rh}$ (right column) deposited $\mathrm{TiO}_{2}(110)-$ $(1 \times 2)$ surfaces $(A)$ at $500 \mathrm{~K}$. The annealing cycles were 5 min at $(B)$ $700 \mathrm{~K}$; (C) $800 \mathrm{~K}$; (D) $900 \mathrm{~K}$; (E) $1000 \mathrm{~K}$; (F) $1100 \mathrm{~K}$. The size of all images is $50 \times 50 \mathrm{~nm}^{2}$.

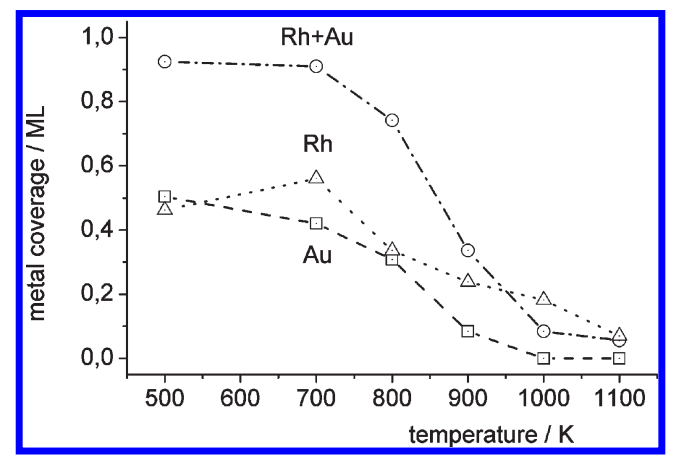

Figure 7. Change of admetal $(\mathrm{Au}, \mathrm{Rh}+\mathrm{Au}, \mathrm{Rh})$ coverage as a function of temperature on $\mathrm{TiO}_{2}(110)-(1 \times 2)$ surfaces for the same experiments presented in Figure 6.

zero in the temperature range $800-1000 \mathrm{~K}$ as is shown also by plotting gold coverage as a function of temperature (Figure 7). Similar thermal treatments were performed for pure Rh (right column in Figure 6). In this case, changes in the morphology and in the metal coverage are more complex than for $\mathrm{Au}$ (Figure 7). The slight increase between 500 and $700 \mathrm{~K}$ of the apparent $\mathrm{Rh}$ total volume is probably due to the encapsulation of $\mathrm{Rh}$ by a reduced phase of the $\mathrm{TiO}_{2}$ substrate. ${ }^{3,28}$ Above this temperature, the amount of the total volume decreases gradually; however, in contrast to $\mathrm{Au}$, the morphological changes refer to a standard Ostwald ripening, where the decrease of the particle number is accompanied by an increase of the average size (both diameter and height). Nevertheless, even in the latter case, some decrease of 


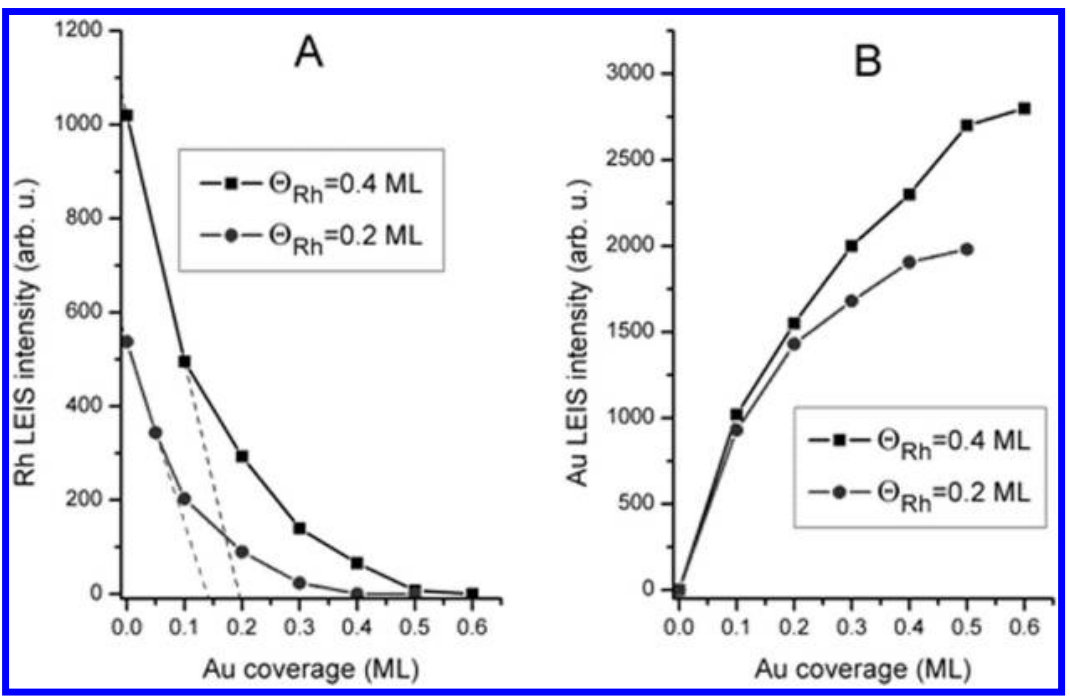

Figure 8. LEIS intensities of (A) Rh and (B) Au as a function of the amount of gold deposited at $500 \mathrm{~K}_{\text {on a }} \mathrm{TiO}_{2}(110) \mathrm{surface}$ precovered by $\mathrm{Rh}(0.20$ and $0.40 \mathrm{ML})$

the total volume can be observed. This feature suggests that a partial desorption of the $\mathrm{Rh}$ atoms in the temperature range 700-1000 K during the Ostwald ripening process cannot be excluded. Note that some highly elongated particles also appear at around $1000 \mathrm{~K}$. The stronger thermal stability of Rh compared to $\mathrm{Au}$ is indicated also by the fact that $\mathrm{Rh}$ particles can be found on the support even after the annealing at $1100 \mathrm{~K}$. Let us remark at this point again that a proper tip conditioning was needed to perform during these experiments in order to make reliable conclusions based on particle volume. In the middle column of Figure 6, the effects of thermal treatment of the $\mathrm{TiO}_{2}(110)-$ $(1 \times 2)$ surface covered by bimetallic $\mathrm{Au}-\mathrm{Rh}$ nanoparticles can be seen. The particles were formed by the seeding + growing procedure presented above. The annealing causes similar changes in the morphology as in the case of the clean Rh nanoparticles, although some differences can also be observed (Figure 6 and 7): (1) the Ostwald ripening is already more pronounced at $800 \mathrm{~K}$; (2) no sign for the elongation of any particle appears. Note that this is the temperature range where the $\mathrm{Au}-\mathrm{Rh}$ mixing can also take place in the bulk phase. ${ }^{32}$ Nevertheless, the stabilized amount of $\mathrm{Rh}$ at $1100 \mathrm{~K}$ is nearly the same for both ( $\mathrm{Rh}$ and $\mathrm{Au}+\mathrm{Rh})$ cases and the size distributions of the particles are similar.

3.2. Low-Energy Ion Scattering Spectroscopy Measurements. In the subsequent experiments, LEIS was applied to collect data about the chemical composition of the nanoparticles formed by deposition of $\mathrm{Rh}$ followed by exposure of $\mathrm{Au}$ on a $\mathrm{TiO}_{2}(110)-(1 \times 1)$ surface. It is important to note that, during the measurements presented below, the surface morphology was not directly monitored by STM. Nevertheless, based on our previous experiences, appropriate thermal and cleaning treatments were chosen to obtain bulk terminated $(1 \times 1)$ surface. Moreover, the scanning tunneling microscopy results presented above clearly show that the main features of the bimetallic $\mathrm{Rh}-\mathrm{Au}$ particle growth is substantially independent from the reconstruction of the support.

Similarly to our previous work, ${ }^{28}$ the deposition of approximately $0.5 \mathrm{ML}$ of $\mathrm{Rh}$ onto clean $\mathrm{TiO}_{2}(110)$ surface led to a substantial decrease $(\sim 30 \%)$ in the Ti and O LEIS peaks due to the shadowing effect of Rh (not shown here). Contrary to that, the deposition of $0.5-0.6 \mathrm{ML} \mathrm{Au}$ on the Rh covered titania surface resulted in a very slight $(5-6 \%)$ decrease in the intensity of Ti and O LEIS peaks (not shown here). Figure 8A exhibits the change of
$\mathrm{Rh}$ signal intensities on the effect of Au deposition at $500 \mathrm{~K}$ for two different Rh coverages $(0.20$ and $0.40 \mathrm{ML}$ with an uncertanity of $\pm 15 \%)$. Although the rate of decay for both curves decreases at higher gold exposures, approximately $0.5 \mathrm{ML}$ deposition of gold was sufficient for a complete suppression of $\mathrm{Rh}$ signal. Note that if only the gold atoms landed on Rh clusters were bonded on the topmost layer of the particles and if gold atoms impinged on the oxide surface formed separate monometallic gold clusters, then $1 \mathrm{ML}$ or an even larger amount of gold would be necessary to cover the existing $\mathrm{Rh}$ clusters and to suppress completely the LEIS intensity of $\mathrm{Rh}$. In our case, however, a much smaller quantity of gold was enough to cover entirely the Rh clusters, which was indicated by the complete disappearance of $\mathrm{Rh}$ signal at gold coverages of $0.45( \pm 0.05) \mathrm{ML}$ (Figure $8 \mathrm{~A})$. Moreover, the steep initial attenuation of the Rh LEIS peak and its early suppression on the effect of Au deposition are in good harmony with the STM measurements presented above, which indicate that gold atoms nucleate exclusively on the existing rhodium clusters. In accordance with our previous investigations, ${ }^{28}$ these LEIS results suggest that there is a clear tendency for $\mathrm{Au}$ atoms to be stabilized on the topmost atomic layer of the bimetallic clusters.

The following evaluation of the initial slopes of the two curves in Figure 8A supports approximately a one-to-one shadowing of surface rhodium atoms by gold atoms. Indeed, before $\mathrm{Au}$ deposition, Rh clusters cover $11 \%$ and $21 \%$ of the oxide surface for $\Theta_{\mathrm{Rh}}=0.2 \mathrm{ML}$ and $\Theta_{\mathrm{Rh}}=0.4 \mathrm{ML}$, respectively, determined from the decrease in the oxide LEIS peaks on the effect of Rh deposition. Dashed lines for the two Rh coverages (Figure 8A) mark the initial slopes of the attenuation of $\mathrm{Rh}$ intensities on the effect of $\mathrm{Au}$ deposition. The extrapolated curves reach the zero $\mathrm{Rh}$ intensity at $\Theta_{\mathrm{Au}}=0.14 \mathrm{ML}$ and $\Theta_{\mathrm{Au}}=0.20 \mathrm{ML}$, respectively. These values agree rather well with the ratio of the oxide surface covered by $\mathrm{Rh}$ and correspond fairly well to those that are expected for one-to-one shadowing. Assuming this scenario, each gold atom deposited on the surface and located on the topmost layer should be detectable by LEIS; consequently, the initial rising slope of the Au signal should be the same for both Rh coverages investigated. Really, this is the case as exhibited in Figure 8B. Nevertheless, above $\Theta_{\mathrm{Au}} \approx 0.2 \mathrm{ML}$ coverage, the LEIS intensity increases less rapidly and the attenuation of $\mathrm{Rh}$ intensity is slower as a function of $\mathrm{Au}$ coverage. This behavior indicates that not every gold atom is on the topmost layer and not every gold atom 


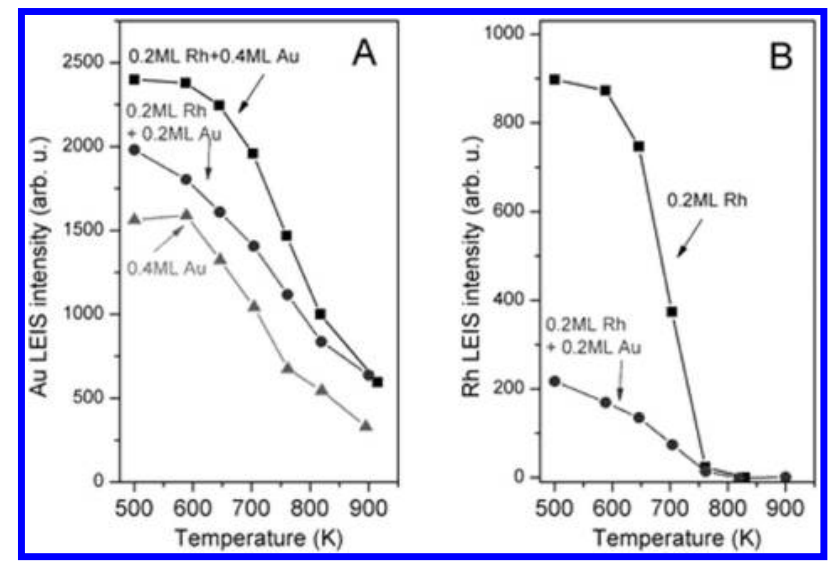

Figure 9. Effects of annealing on LEIS intensities of (A) Au and (B) $\mathrm{Rh}$. The sample was kept for 5 min at each temperature. The corresponding metal coverages are indicated in the figure.

can shadow one Rh atom anymore. Naturally, the question may arise as to why the decrease in the Rh intensity as a function of $\mathrm{Au}$ coverage is not linear in the full range. One possible reason is that $\mathrm{Rh}$ atoms located at defect sites of the clusters (e.g., edge atoms or kinks) cannot be shadowed so efficiently, i.e., a thicker gold layer is needed to cover these sites also. Moreover, to obtain a complete capping layer, more gold atoms are needed than the number of $\mathrm{Rh}$ atoms located on the topmost layer of the original clusters, because metal atoms at the perimeter should be covered from the side. For $\Theta_{\mathrm{Rh}}=0.2 \mathrm{ML}$, the mean diameter of Rh clusters is $1.5 \mathrm{~nm}$ disclosed by our STM studies. With a one atomic layer thick gold shell, the mean diameter is increased up to $2.0 \mathrm{~nm}$, resulting in an $80 \%$ increase in the cluster footprint area. In addition, we cannot exclude some mixing of gold and rhodium atoms inside the nanoparticles, though the two metals are practically immiscible in bulk phase. However, it can be concluded from our LEIS and STM results presented above that the mixing of $\mathrm{Au}$ and $\mathrm{Rh}$ in the bimetallic nanoparticles is very limited (if any).

In the subsequent LEIS measurements, we focused on thermally induced behavior of the core-shell structure prepared at $500 \mathrm{~K}$. Annealing of the $\mathrm{Au} / \mathrm{TiO}_{2}$ surface at higher temperatures led to diminution of the Au LEIS peak accompanied by an increase in the oxide peaks (not shown). In accordance with the STM results, this tendency can be explained by agglomeration and evaporation of gold (Figure 9A). When gold is deposited at $500 \mathrm{~K}$ to the titania surface precovered by $0.2 \mathrm{ML}$ of $\mathrm{Rh}$, the $\mathrm{Au}$ LEIS peak exhibits larger intensity. This feature can be understood easily, since gold atoms are located on top of the smaller $\mathrm{Rh}$ clusters, i.e., the dispersion of gold is larger. On annealing the $\mathrm{Au}+\mathrm{Rh} / \mathrm{TiO}_{2}$ surface, agglomeration and evaporation of gold may also take place; nevertheless, the Au LEIS intensities were significantly higher at each temperature compared to a $\mathrm{Rh}$ free titania surface covered by the same amount of gold (Figure 9A). In conclusion, the presence of rhodium resulted in a significantly enhanced dispersion of $\mathrm{Au}$ at each temperatures up to $900 \mathrm{~K}$.

In the case of annealing the Rh covered surface (containing no gold), a dramatic decrease in the intensity of the Rh LEIS peak was found above $650 \mathrm{~K}$, and the rhodium signal completely disappeared at $\sim 800 \mathrm{~K}$ (Figure 9B). This latter feature can be explained mainly by the encapsulation of Rh clusters with a thin titania layer, especially if we take into account the STM images indicating insignificant evaporation and sintering of $\mathrm{Rh}$ in this temperature range. The deposition of $0.20 \mathrm{ML}$ of gold on the titania surface covered by $\mathrm{Rh}$ is not enough to completely cover
Rh clusters at $\Theta_{\mathrm{Rh}}=0.20 \mathrm{ML}$ (Figure 9B). Nevertheless, some attenuation of the Rh peak was also observed in this case from 600 to $650 \mathrm{~K}$, and after annealing at $800 \mathrm{~K}$, the $\mathrm{Rh}$ peak was completely missing. The $\mathrm{Rh}$ peak disappeared at the same temperature in both the presence and absence of gold. This fact suggests that titania will also decorate $\mathrm{Rh}$ atoms of the bimetallic clusters not covered by gold upon annealing. Another possibility is that gold is not well arranged for shadowing Rh clusters at $500 \mathrm{~K}$, and upon annealing, it covers better the rhodium core leading to the disappearance of the Rh peak. Consequently, the formation of a more complete gold shell would result in an increase in the gold signal at 650-700 K; however, an increase in the gold signal was not observed (Figure 9A). Note that, in this temperature range, the decrease of $\mathrm{Rh}$ intensity is already strong, in spite of only a very slight agglomeration of the bimetallic clusters. On this basis, it can be concluded that the disappearance of Rh LEIS-signal is mainly due to the encapsulation by titania, also operating for bimetallic clusters.

As mentioned above, deposition of $0.40 \mathrm{ML}$ of Au at $500 \mathrm{~K}$ on the titania surface covered previously by $0.20 \mathrm{ML}$ Rh resulted in complete disappearance of the Rh LEIS peak, and it did not reappear on stepwise annealing up to $900 \mathrm{~K}$. To understand this observation, let we consider first only the temperature regime up to $800 \mathrm{~K}$, for which the evaporation of both gold and rhodium is rather limited (Figures 7 and 9A). STM measurements presented in Figure 6 disclosed that the cluster density was smaller both for the $\mathrm{Rh} / \mathrm{TiO}_{2}$ surface and for the $(\mathrm{Rh}+\mathrm{Au}) / \mathrm{TiO}_{2}$ surface as compared to that observed at $500 \mathrm{~K}$, accompanied by the increase of the average cluster size up to $800 \mathrm{~K}$ (compare Figure 6A and C). This feature is a clear indication that the detachment of both $\mathrm{Rh}$ and $\mathrm{Au}$ atoms from the metal clusters is possible in this temperature range and this is followed by their diffusion on the oxide surface (Ostwald ripening). This process is probably more frequent for Au atoms. Hence, in principle, the replacement of the gold capping layer on $\mathrm{Rh}$ by the titanium oxide encapsulating layer is not kinetically hindered during annealing at $800 \mathrm{~K}$, which could explain the Rh LEIS intensity remaining at zero. However, in this case separate monometallic gold clusters should form on the free oxide surface; consequently, the Au LEIS intensity should be the same as observed for the Rh-free surface for the same gold coverage. In contrast to this, for all temperatures depicted in Figure 9A, the LEIS intensities of Au for the surface containing $0.2 \mathrm{ML}$ of Rh and 0.4 ML of Au were nearly twice as large as for the surface containing no rhodium. On the basis of this observation, it seems very probable that $\mathrm{Rh}$ clusters remain covered by gold even during the ripening process (aside from transient fluctuations) and a titanium oxide encapsulating layer cannot be formed in a stable way until there is enough gold on the surface. The relatively strong $\mathrm{Au}-\mathrm{Rh}$ bonding also supports this explanation. ${ }^{33}$ At higher temperatures $(900-1000 \mathrm{~K})$, however, the evaporation of gold opens the way for the encapsulation of $\mathrm{Rh}$ clusters. The desorption of Au atoms does not occur directly from metal clusters, but it proceeds probably during the migration of isolated gold atoms on the oxide. This mechanism is supported by a former study, where it was found that a much higher temperature $(\sim 1325 \mathrm{~K})$ is needed for evaporation of $\mathrm{Au}$ from the $\mathrm{Rh}(111)$ surface. $^{33}$

\section{Discussion}

4.1. Role of Surface Diffusion in Formation of $\mathbf{R h}-\mathrm{Au}$ Core Shell Nanoparticles on $\mathrm{TiO}_{2}(110)$ Surface. The physical vapor deposition is certainly the most substantial "bottom-up" preparation technique of 2D model catalysts where metal atoms 
or nanoclusters of few atoms are deposited onto well-characterized (oxide) surfaces followed by thermal activation of their surface diffusion and sintering. The standard nucleation theory describes well the formation of nanoparticles by using only a few parameters like (1) deposition rate, (2) activation energy for atom diffusion on the support surface (diffusion coefficient), (3) heterogeneous nucleation determined by defect sites, (4) nucleon-size dependence of the atom-particle bond strength, and (5) critical cluster size for homogeneous nucleation. ${ }^{1,10,42}$ Naturally, the real systems are much more complicated. Other important factors must frequently be taken into account, for example, (a) different bonding states for the diffusing atoms (periodic and nonperiodic defect sites); (b) atom diffusion on the perimeter or on the surface of the nucleons; (c) formation of large nucleons of multilayers, change from 2D growth to 3D; (d) coverage-dependent reconstruction of the substrate; (e) chemical reaction between the admaterial and the substrate. Nevertheless, all these parameters can be treated by robust Monte Carlo simulations, especially if their effects can separately be taken into account using ab initio calculations. $^{2,43,44}$

On the metal $/ \mathrm{TiO}_{2}$ interfaces, throughout the past decade widespread theoretical and experimental studies have been performed on these systems, mainly because of their fundamental and technological importance. ${ }^{2,3,25}$ The recent STM results obviously gave new life even to the theoretical efforts for understanding metal diffusion on real $\mathrm{TiO}_{2}$ surfaces. ${ }^{45,46}$ This is mainly because the bulk terminated $\mathrm{TiO}_{2}(110)$ is precisely characterized by STM and also the typical defect sites are well-understood on this surface. ${ }^{25}$ It was shown experimentally that the nucleation probability can be enhanced by forming additional surface defects: $(1)$ on the thermally reduced $(1 \times 1)$ or $(1 \times 2)$ surface relative to the stoichiometric $(1 \times 1)$ substrate, the deposited $\mathrm{Au}$ forms smaller size crystallites in higher density; ${ }^{47-49}$ (2) the same effect was detected for $\mathrm{TiO}_{2}(110)$ surface bombarded by lowenergy Ar ions. ${ }^{29}$ Consistent with this, Iddir and co-workers have shown in their recent theoretical work that, though there is a substantial difference in the bonding of $\mathrm{Pt}$ and $\mathrm{Au}$ to the $\mathrm{TiO}_{2^{-}}$ (110) surface, their binding energies are much higher (by approximately $2 \mathrm{eV}$ ) at the oxygen vacancies. ${ }^{45}$ To the best of our knowledge, similar calculations are not available for Rh; nevertheless, assuming that the chemical properties of $\mathrm{Rh}$ are not far from those of $\mathrm{Pt}$, this finding fits well with our observation in the present work that the surface concentration of $\mathrm{Rh}$ seeds formed on a $\mathrm{TiO}_{2}(110)-(1 \times 2)$ surface is higher (their average size is smaller) than on a stoichiometric $(1 \times 1)$ surface (Figure 2 and Figure 4). Moreover, the observed preference for bonding of $\mathrm{Rh}$ on the reduced $\mathrm{Ti}_{2} \mathrm{O}_{3}$ stripes of the $(1 \times 2)$ reconstructed surface (especially after annealing at higher temperatures) also supports the theoretical predictions mentioned above. The stronger $\mathrm{Rh}-\mathrm{TiO}_{2}$ bonding, relative to that for $\mathrm{Au}-\mathrm{TiO}_{2}$, expresses itself in the higher dispersion of $\mathrm{Rh}$ of similar amount on the $\mathrm{TiO}_{2}$ $(110)-(1 \times 1)$ surface (Figure 6$)$. This agrees with the tendency described by Iddir et al. that Pt displays a one-dimensional

(42) Zinke-Allmang, M.; Fedman, L. C.; Grabow, M. H. Surf. Sci. Rep. 1992, 16,377 .

(43) Zhdanov, V. P.; Kasemo, B. Surf. Sci. Rep. 2000, 39, 25.

(44) Jensen, P.; Larralde, H.; Meunier, M.; Pimpinelli, A. Surf. Sci. 1998, 412 413,458

(45) Iddir, H.; Öğüt, S.; Browning, N. D.; Disko, M. M. Phvs. Rev. B 2005, 72, 081407.

(46) Asaduzzaman, A. M · Krüger, P Phvs. Rev, B 2007, 76, 115412

(47) Min, B. K.; Wallace, W. T.; Goodman, D. W. Surf. Sci. 2006, 600, L7.

(48) Madea, Y.; Fujitani, T.; Tsubota, S.; Maruta, M. Surf. Sci. 2004, 562, 1.

(49) Park, J. B.; Graciani, J.; Evans, J.; Stacchiola, D.; Ma, S.; Liu, P.; Nambu, A.; Sanz, J. F.; Hrbek, J.; Rodriguez, J. A. Proc. Natl. Acad. Sci. U.S.A. 2009, 106, 4975 . migration profile, while the migration of $\mathrm{Au}$ is two-dimensional with a relatively flat profile. ${ }^{45}$ Actually, this large difference between the diffusion properties of $\mathrm{Au}$ and other noble metals (Pt, Ir, Rh) makes it possible that Au atoms can further grow Rh seeds formed previously. The LEIS and STM results presented in this work clearly indicate that the gold atoms are sufficiently mobile at $500 \mathrm{~K}$ on both the $\mathrm{TiO}_{2}(110)-(1 \times 1)$ and $(1 \times 2)$ surfaces to diffuse and nucleate on the Rh seeds located in an average distance not more than 4-6 nm.

An interesting point of our STM-LEIS studies on the effect of annealing of the oxide sample decorated by $\mathrm{Au}-\mathrm{Rh}$ bimetallic particles is that it can be regarded as a special case of Ostwald ripening where the Au shelled $\mathrm{Rh}$ particles are sintering gradually without losing their gold cap. This is certainly a dynamic process where $\mathrm{Rh}$ atom detachment and diffusion are much slower than those of $\mathrm{Au}$; moreover, the $\mathrm{Au}-\mathrm{Rh}$ exchange on the particles is probably a reaction step of higher speed. ${ }^{32,50}$ It is worth mentioning that choosing low coverages in this work allowed us to follow the mass transport mediated almost exclusively by the support; accordingly, the growth by particle coalescence was practically negligible. Although compact diffusion of smallest (consisting of max. 50 atoms) nanoparticles cannot be excluded, ${ }^{19}$ taking into account the particle size distribution in our case, the main route of the particle growth is certainly atom detachment, diffusion, and condensation both for $\mathrm{Rh}$ and for $\mathrm{Au}$.

In the case of reducible oxides, like $\mathrm{TiO}_{2}, \mathrm{SnO}_{2}$, and $\mathrm{CeO}_{2}$, there is another complicating factor affecting the sintering of the supported noble metals: the encapsulation (decoration) of the metal nanoparticles by a reduced phase of the support. ${ }^{3}$ In harmony with the previous studies, the formation of $\mathrm{Rh}-\mathrm{Au}$ core-shell particles described in this work was performed at relatively low temperature $(500 \mathrm{~K})$ where the decoration process is practically negligible (especially for stoichiometric $\mathrm{TiO}_{2}$ support). ${ }^{18,28,40,51}$ More attention was paid for this effect of the oxide decoration during the sintering process of the bimetallic particles (see below). It is worth mentioning that, in a previous work of ours, the encapsulated Pt particles were successfully postgrown at $1100 \mathrm{~K}$ in a way that the thickness of the decoration $\mathrm{TiO}_{x}$ layer was self-limiting and the additional $\mathrm{Pt}$ atoms could be built in the Pt nanoparticles. ${ }^{52}$ Furthermore, the overview of the encapsulation process of different supported metals renders $\mathrm{Rh}$ to the group of metals more easily decorated and $\mathrm{Au}$ to those that are not encapsulated by a thin $\mathrm{TiO}_{x}$ layer. ${ }^{3}$

4.2. Composition of Supported Rh-Au Core-Shell Nanoparticles. Regarding the surface diffusion of noble metals, both metal-on-metal and metal-on-oxide atom diffusion are already activated at room temperature. At the same time, the metal-metal bonding is characteristically stronger than the metal-oxide bond, which means that the metal adatoms will be condensed at the existing metal particles of high probability. Accordingly, most of the supported metal nanoparticles exhibit an isotropic lateral shape. It should be mentioned, however, that in special cases (for example, metal deposits on cation-terminated oxide surfaces) and/or at certain conditions (growth at high temperatures), formation of one-dimensional elongated metal particles were also observed. ${ }^{34,53,54}$ This property may be explained by formation of oxygen-deficient sites at the particle

(50) Locatelli, A.; Heun, S.; Kiskinova, M. Surf. Sci. 2004, 566-568, 1130.

(51) Ovári, L.; Kiss, J. Appl. Surf. Sci. 2006, 252, 8624.

(52) Szöko, J.; Berkó, A. Vacuum 2003, 71, 193.

(53) Katsiev, K.; Batzill, M.; Diebold, U.; Urban, A.; Meyer, B. Phvs. Rev. Lett. 2007, 98, 186102.

(54) Humphrey, D. S.; Cabailh, G.; Pang, C. L.; Muryn, C. A.; Cavill, S. A.; Marchetto, H.; Potenza, A.; Dhesi, S. S.; Thornton, G. Nano Lett. 2009, 9(1), 155. 
perimeter, resulting in an anisotropic wetting of the support and in an anisotropic growth of the admetal. This feature was clearly detected during the present investigations when the $0.46 \mathrm{ML} \mathrm{Rh}$ deposited $\mathrm{TiO}_{2}(110)-(1 \times 1)$ surface was annealed at $1000 \mathrm{~K}$ (Figure 6E). On the basis of our experiments, it can also be concluded that, when the perimeter chemical composition changed by the codeposition of $\mathrm{Au}$, the growth of elongated particles is largely hindered (Figure 6).

The parallel increase of the height and width of the bimetallic particles with the duration of Au deposition suggests that Au does not accumulate at the perimeter of the Rh particles, or in other words, $\mathrm{Au}-\mathrm{Rh}$ particle pairs never form. The sharp decrease of the Rh LEIS signal on the effect of Au deposition indicates clearly that $\mathrm{Au}$ atoms readily jump over the diffusion barrier at the edge of the particles (maybe covered partially by gold from the very beginning of the Au deposition) and they cover the Rh seeds by layer-by-layer growth mode (Figures 3 and 5). The large difference between the surface free energies of the two metals (at room temperature $1.626 \mathrm{~J} / \mathrm{m}^{2}$ for Au and $2.828 \mathrm{~J} / \mathrm{m}^{2}$ for $\mathrm{Rh}$ ) is probably the main driving force for this phenomenon. ${ }^{23,31}$ The accumulation of gold on Rh-seeds at $500 \mathrm{~K}$ is an irreversible process, since the $\mathrm{Rh}-\mathrm{Au}$ bond is much stronger on average than that of Autitania (except some titania defect sites).

This behavior of the predeposited $\mathrm{Rh}$ and postdeposited $\mathrm{Au}$ on $\mathrm{TiO}_{2}(110)$ surface is not a unique feature for the bimetallic systems. The site-selective accumulation of a postdeposited metal (forming shell) on predeposited metal particles (representing core)-formation of core-shell bimetallic particles on oxide surfaces - was already reported in several cases: $\mathrm{Co}-\mathrm{Pd},{ }^{15,16}$ $\mathrm{Pd}-\mathrm{Fe},{ }^{17} \mathrm{Pt}-\mathrm{Au} .{ }^{20}$ In order to obtain really high grade coreshell structures, there are several conditions to be fulfilled: (i) the metal sequence of the deposition is very crucial; the "core" metal should be the stronger wetting metal and it should be deposited first; (ii) the immiscibility of the metals (in bulk) is an important factor, but even in this case, a few percentage mixing can appear; (iii) using miscible metals, the intermixing of the deposited metals is so strong that it prevents the formation of core-shell structure even below room temperature; (iv) the shell-metal should have a much lower surface free energy than that of the core-metal.

A similar investigation of annealing $\mathrm{Pt}$ and $\mathrm{Pt}-\mathrm{Au}$ clusters grown on $\mathrm{TiO}_{2}(110)$ disclosed that the encapsulation by titania proceeded in both cases; however, the presence of gold in the outermost layer (shell) of the bimetallic clusters substantially decreased the extent of the encapsulation. ${ }^{20}$ In the past years, the encapsulation process was examined in detail. . $^{3,18,25,28,40,51,55} \mathrm{It}$ has been proposed that minimization of the surface energy is the major driving force of the encapsulation of metal clusters by an oxide overlayer. ${ }^{3}$ It can proceed only in the systems where the metal has high surface energy while the surface energy of the oxide is low. Accordingly, the surface energetic factor explains why Pt, $\mathrm{Pd}$, and $\mathrm{Rh}$, but not $\mathrm{Au}$ and $\mathrm{Ag}$, have been subjected to this reaction on titania. Moreover, the interfacial energy between these latter metals and $\mathrm{TiO}_{2}$ is very low, which also hinders the encapsulation. From the chemical point of view, it was assumed that the decoration by the support oxide can proceed if the metal

(55) Sadeghi, H. R.; Henrich, V. E. Appl. Surf. Sci. 1984, 19, 330. is able to reduce titania but is not reactive enough to form bulk oxide. ${ }^{56}$ The gold shell may also keep the Rh particles free from the encapsulation by titania, as it was demonstrated by the LEIS experiments above. The facts that Au is covering the Rh particles, this structure is stable at high temperatures, and the strong $\mathrm{Au}-\mathrm{Rh}$ interaction modifies the electronic structure of the components open the way for very specific catalytic applications.

\section{Conclusions}

The formation of bimetallic nanoparticles on solid surfaces is a complex process, which is determined by both the thermodynamic characteristics of the bonding between the components and the kinetics of the surface diffusion of the partner materials. These attributes were exploited in this work for growth of supported bimetallic core-shell $\mathrm{Rh}-\mathrm{Au}$ nanoparticles on a $\mathrm{TiO}_{2}(110)-$ $(1 \times 1)$ and $(1 \times 2)$ surfaces. The oxide support seeded by $\mathrm{Rh}$ at $500 \mathrm{~K}$ was exposed to $\mathrm{Au}$ also at the same temperature. It was shown by low-energy ion scattering that the Rh-seeds became shadowed very sharply (with a rate of close to one-to-one atom) on the initial deposition of gold and a complete capping was achieved at a substantially lower deposition than would be expected from a simple surface decoration model. The parallel STM measurements completed by statistical image evaluation revealed clearly that the existing $\mathrm{Rh}$ seeds are grown in both width and height without appearance of of a new nucleus on the free regions of the substrate. It means that the postdeposited Au atoms accumulate exclusively on the existing Rh particles; moreover, the 1-2 ML thick cap consists practically of pure gold. This mechanism is valid for the supported Rh seeds closer to each other than the mean free path of $\mathrm{Au}$ diffusion. This latter parameter, however, largely depends on the composition of the $\mathrm{TiO}_{2}(110)$ surface and the deposition rate applied for postgrowth of $\mathrm{Au}$. In the case of a bulk terminated $\mathrm{TiO}_{2}(110)-(1 \times 1)$ surface and of a deposition rate of approximately $0.5 \mathrm{ML} / \mathrm{min}$, this critical distance is in the range $8-10 \mathrm{~nm}$; however, in the case of a more reduced $\mathrm{TiO}_{2}(110)-(1 \times 2)$ surface this value is only $4-6 \mathrm{~nm}$.

The thermal stability of monometallic $\mathrm{Rh}, \mathrm{Au}$, and bimetallic $\mathrm{Au}-\mathrm{Rh}$ nanoparticles was also examined and compared. The experimental results suggested that the Ostwald ripening proceeds similarly for the monometallic and bimetallic nanoparticles and in this way until the evaporation of $\mathrm{Au}$ from the surface, the fattening $\mathrm{Rh}$ particles are continuously capped by $\mathrm{Au}$, although the disengaged surface of the $\mathrm{Rh}$ particles are probably encapsulated by the phase of the support.

In short, it was proven that bimetallic nanoparticles could be grown in tailored structural composition by choosing appropriate deposition conditions. The research activity in this direction hopefully opens the way for widespread surface science model studies of catalytic properties of Au-shell bimetallic nanoparticles.

Acknowledgment. The Hungarian Scientific Research Fund (OTKA) through K-69200 and NI-69327 projects financially supported this work. The authors thank gratefully for the valuable discussions to Dr. László Bugyi.

(56) Pesty, F.; Steinrück, H.-P.; Madey, Th. E. Surf. Sci. 1995, 339, 83. 